\title{
Knowledge, Attitudes and Practices of Pregnant Women Attending the Antenatal Clinic of Rivers State University Teaching Hospital, Nigeria towards the Coronavirus (COVID-19) Pandemic
}

\author{
Boma Awoala West ${ }^{1}$, Josephine Enekole Aitafo ${ }^{2}$, Dango Genesis Bietonka Kalio ${ }^{3}$ \\ ${ }^{1}$ Consultant Paediatrician, Department of Paediatrics, Rivers State University Teaching Hospital, No 6-8 Harley \\ Street, Old GRA, Port Harcourt, Nigeria \\ ${ }^{2}$ Consultant Paediatrician, Department of Paediatrics, Rivers State University Teaching Hospital, No 6-8 Harley \\ Street, Old GRA, Port Harcourt, Nigeria \\ ${ }^{3}$ Consultant, Obstetrics \& Gynecology, Department of Obstetrics \& Gynecology, Rivers State University \\ Teaching Hospital, No 6-8 Harley Street, Old GRA, Port Harcourt, Nigeria \\ Corresponding Author: Boma Awoala West
}

\begin{abstract}
Background: COVID-19, a new respiratory infection was declared a global pandemic in 2020. Pregnant women are at risk because of their physiologic and immunologic changes. Preventive measures are essential as there is no definite cure. This study was therefore carried out to determine the knowledge, attitudes and practices of pregnant women attending antenatal clinic of Rivers State University Teaching hospital, Nigeria towards the COVID-19 pandemic.

Materials and Methods: This cross-sectional questionnaire-based study was conducted at the antenatal clinic of the hospital over 6weeks. Scores assessing knowledge, attitudes and practices were allocated and graded based on specific stratified demarcations.

Results: Two hundred and six respondents $(81.4 \%)$ were assessed to have good knowledge. Fifty-one (20.2\%) had overall good attitude while $67(26.5 \%)$ had good practice of preventive measures. The commonest symptoms of COVID-19 recalled were cough 169(27.8\%), shortness of breath $153(25.1 \%)$ and fever 145(23.7\%). Parity, mother's and spouse's level of education and occupation were significantly associated with knowledge levels while age of the mothers was associated with the attitude towards COVID-19 infection. Parity, mother's and spouse's level of education and occupation were significantly associated with the practice levels. There was an association of good knowledge and good attitude levels with good practice level ( $p>0.05)$.

Conclusion: Although pregnant women in Port Harcourt generally had good knowledge, majority of them had poor attitude and practice towards the pandemic. We therefore recommend strengthening public health education campaigns (including via antenatal clinic health talks, television and social media), providing evidence-based policies and debunking of wrong beliefs.
\end{abstract}

Keywords: COVID-19; Knowledge; Attitude; Practice; Pregnant women

\section{INTRODUCTION}

Covid-19, a new respiratory infection that first began in Wuhan province of China is caused by a novel coronavirus 2 (SARS-CoV 2). It causes severe acute respiratory syndrome which has rapidly spread all over the world, to over 110 countries including Nigeria thus prompting the World Health Organisation (WHO) to declare it a pandemic on March $11^{\text {th }}$, 2020. ${ }^{[1-3]}$ This disease which is a problem of global concern, has led to serious global economic impact and has contributed significantly to increased mortality 
including men, women and even children all around the world. ${ }^{[4]}$

Patients infected with Covid-19 are either asymptomatic or present with symptoms ranging from a common cold to a severe acute respiratory failure. ${ }^{[2,5]}$ Symptoms also include fever, sore throat, new loss of taste/smell, progressive difficulty in breathing and features of hypoxia in severe cases. ${ }^{[1,5-7]}$ Studies have also included vomiting, diarrhoea, neurologic features and features of renal impairment in the symptomatology of the disease. $^{[1,6,7]}$

As there is still no definite cure, preventive measures are thus essential as the only method to protect people against this infection. $^{[5,8]}$

Nigeria, the most densely populated country in Africa is of great concern with regards to this pandemic because of its' population of over 200million. ${ }^{[6]}$ Pregnant women are considered to be more susceptible to developing severe cases or mortality with COVID-19 infection when compared with the general public because of the physiologic and immunologic changes of pregnancy. ${ }^{[5,9,10]}$ Furthermore, the presence of comorbidities, high body mass index and higher maternal age are considered as risk factors for developing more severe infection in pregnant women. $^{[5,11]}$ Prevention of COVID-19 infection is therefore critical for pregnant women.

To prevent the spread of COVID-19 infection and its associated mortality, the World Health Organisation (WHO) has recommended preventive/safety measures including frequent hand washing with soap and water, physical/social distancing, the use of face mask in public, covering the mouth while coughing and avoiding touching the eyes, nose and mouth. ${ }^{[9,12]}$

Knowledge and attitude play key roles in the prevention of infectious diseases including COVID-19. Inadequate knowledge may lead to delay in the diagnosis of this highly infectious disease, spread of the disease with poor infection control practices. ${ }^{[13]}$ This study is therefore being carried out in our centre to evaluate the knowledge, attitudes and practices of pregnant women attending the Antenatal clinic(ANC) in the Rivers State University Teaching Hospital (RSUTH) towards the COVID-19 pandemic. This study thus assesses how much pregnant women in Port Harcourt know about the disease, their attitude towards it as well as how well they practice the guidelines and recommendations that have been put in place.

\section{MATERIALS AND METHODS}

This study was a cross-sectional questionnaire-based study carried out in the Antenatal Clinic (ANC) of the Rivers State University Teaching Hospital (RSUTH) Nigeria over six weeks from $18^{\text {th }}$ of January, 2021 to $5^{\text {th }}$ of March, 2021. The ANC runs from Mondays to Fridays, $8 \mathrm{am}$ to $4 \mathrm{pm}$ with Consultants, Resident doctors and House Officers seeing an average of 60 patients each day.

The RSUTH, a tertiary hospital owned by the Rivers State Government, located in the down town area of the state, is a 375 bedded hospital which serves as a referral centre for all the government owned Primary Health Care facilities, general hospitals and private health facilities in the state as well as neighbouring states.

Prior to commencement of the study, the research team comprising the researchers and 3 research assistants (house officers) underwent a structured training conducted by the lead researcher on proper administration of the pre-tested and validated questionnaire. Strict COVID-19 safely protocols were adhered to with research assistants and participants wearing face mask and maintenance of physical distancing. Writing pens were provided for each participant which were not retrieved thereafter.

The proposed study was explicitly explained to the women attending ANC and informed consent was obtained before the questionnaire was administered. Ethical 
approval (RSUTH/REC/2021047) was also obtained from the RSUTH Health Research Ethics Committee.

With a convenient sampling size of 253 participants, mothers attending ANC at RSUTH irrespective of their parity and who gave informed consent were randomly recruited for the study. Non-pregnant women and pregnant women who did not give consent were excluded from the study.

The research Proforma was administered to each recruited mother. The information obtained included their demographic characteristics and parity, questions assessing the participant's knowledge of COVID-19 including causes, symptoms, transmission and prevention. It also included questions assessing their attitude towards the preventive measures, willingness to take the COVID-19 test, willingness to receive the vaccine and have their children vaccinated when it is made available. Questions concerning their practice of the safety measures such as social/physical distancing, handwashing, use of hand sanitizers and face masks were also assessed. Scores assessing knowledge, attitudes and practices were allocated and graded based on specific stratified demarcations. A correct answer was assigned 1 point while an incorrect or 'I don't know' was assigned zero. Thirteen points were allocated to the section on knowledge. Mothers were determined to have good knowledge of the COVID-19 pandemic and safety measures if they had at least $70 \%$ and above (9-13) correct responses to the questions in the section on knowledge. Knowledge was said to be poor if the correct responses were less than $70 \%$ $(<9)$. Seven points were allocated to the section on attitude, of which mothers were said to have good attitude if they had at least $70 \%$ and above (5-7) positive responses to the questions in this section. Attitude was poor if the positive responses were less than $70 \%(<5)$. Thirteen points were allocated to the section on the practice of the safety measures, of which mothers were said to have good practice if they had $70 \%$ and above (9-13) positive responses to the questions in this section. Practice was said to be poor if the positive responses were less than $70 \%(<9)$.

All the information obtained were entered into an excel spreadsheet and data analysed using SPSS version 23. Data was presented as frequency and percentages for categorical variables, and as means and standard deviations for continuous variables. All items used in assessing knowledge, attitudes and practices were first recoded, summed and then classified into Good and Poor respectively. Fishers' Exact and Chi-square tests (where indicated) were used in determining the association between socio-demographic characteristics and the outcome variables (Knowledge level, attitude level and practice level, respectively). Association between outcome variables were determined and its strength tested with Binary logistic regression. Test of Statistical significance was set at $95 \%$ confidence interval with $\mathrm{P}$ value $<0.05$.

\section{RESULT \\ Sociodemographic characteristics of respondents}

Of 253 respondents, age group 2938years predominated $154(60.9 \%)$ with a mean age of $30.78 \pm 4.71$ years. Most respondents were nulliparous $71(28.1 \%)$, married $249(98.4 \%)$ and resided in urban areas $235(92.9 \%)$. Majority attained tertiary education and were mainly artisan/business women/petty traders 126(49.8\%). The husbands of the respondents had mainly tertiary education $173(68.4 \%)$ and were businessmen and petty traders 59(23.4\%), Table I.

\section{Knowledge of COVID-19 pandemic}

Two hundred and fifty-one (99.2\%) respondents had heard of COVID-19 with their source of information being mainly television $132(32.6 \%)$, radio $88(21.7 \%)$ and social media $78(19.3 \%)$. One hundred and sixty-six respondents knew the causative organism of COVID-19 being of viral origin and the mode of transmission being droplets 
Boma Awoala West et.al. Knowledge, attitudes and practices of pregnant women attending the antenatal clinic of Rivers State University Teaching Hospital, Nigeria towards the coronavirus (COVID-19) pandemic.

$148(38.2 \%)$ and contact with infected surfaces $126(32.6 \%)$. One hundred and five (41.5\%) respondents knew COVID-19 could be transmitted from mother to child and the mode of transmission being via droplets from infected mother after birth $44(17.3 \%)$, trans-placental $27(10.7 \%)$ and via breastmilk 21(8.3\%). Only 61(24.2\%) of respondents knew COVID-19 infected mother could breastfeed their babies, $176(69.6 \%)$ believed the infection can be treated while 231(91.3\%) knew it can be prevented. Two hundred and forty-two $(95.7 \%)$ knew it could lead to death and the population at risk of death being majorly the elderly 223(92.1\%). Two hundred and six respondents $(81.4 \%)$ were assessed to have good knowledge while $47(18.6 \%)$ had poor knowledge of COVID-19 infection, Table II.

Table I: Sociodemographic characteristics of respondents

\begin{tabular}{|lc|}
\hline Characteristics & Frequency, \\
$\mathbf{n}=\mathbf{2 5 3}(\%)$ & \\
\hline Age groups (years) & \\
$19-28$ & $82(32.4)$ \\
$29-38$ & $154(60.9)$ \\
$\geq 39$ & $17(6.7)$ \\
Parity & $71(28.1)$ \\
Nil & $62(24.5)$ \\
One & $63(24.9)$ \\
Two & $57(22.5)$ \\
Three or more & \\
Marital status & $4(1.6)$ \\
Single & $249(98.4)$ \\
Married & \\
Area of residence & $235(92.9)$ \\
Urban & $18(7.1)$ \\
Rural & \\
Mother's level of education & $8(3.2)$ \\
No formal education & $6(2.4)$ \\
Primary & $74(29.2)$ \\
Secondary & $165(65.2)$ \\
Tertiary & \\
Mother's occupation & $53(20.9)$ \\
Civil/Public servant & $126(49.8)$ \\
Artisan/Business/Trader & $27(10.7)$ \\
Health workers/Professional & $47(18.6)$ \\
Housewife/unemployed & \\
Husband's level of education & $6(2.3)$ \\
No formal education & $10(4.0)$ \\
Primary & $64(25.3)$ \\
Secondary & $173(68.4)$ \\
Tertiary & \\
Husband's occupation & $57(22.5)$ \\
Civil/public servant & $59(23.4)$ \\
Business/Trader & $54(21.3)$ \\
Health worker/professional & $43(17.0)$ \\
Artisan & $40(15.8)$ \\
Unemployed & \\
& \\
\hline &
\end{tabular}

Table II: Knowledge of COVID-19 pandemic

\begin{tabular}{|c|c|}
\hline $\begin{array}{l}\text { Variables } \\
\mathrm{n}=\mathbf{2 5 3}(\%) \\
\end{array}$ & Frequency, \\
\hline \multicolumn{2}{|l|}{ Have you heard of COVID-19? } \\
\hline Yes & 251(99.2) \\
\hline No & $2(0.8)$ \\
\hline \multicolumn{2}{|l|}{ What was your source of information? $\left(n^{*}=405\right)$} \\
\hline Television & 132(32.6) \\
\hline Radio & 88(21.7) \\
\hline Social media & $78(19.3)$ \\
\hline Health worker & $56(13.8)$ \\
\hline Friends & $31(7.7)$ \\
\hline Relatives & $20(4.9)$ \\
\hline \multicolumn{2}{|l|}{ What is the cause of COVID-19? } \\
\hline Viral infection & $166(65.6)$ \\
\hline Bacterial infection & 24(9.5) \\
\hline Fungal infection & $1(0.4)$ \\
\hline Man-made organism & $8(3.2)$ \\
\hline $5 \mathrm{G}$ network & $10(4.0)$ \\
\hline Don’t know & 44(17.3) \\
\hline \multicolumn{2}{|c|}{ What is the mode of transmission of COVID-19? $\left(n^{*}=387\right)$} \\
\hline Droplets from air & 148(38.2) \\
\hline Contact with infected surfaces & $126(32.6)$ \\
\hline Blood products & 19(4.9) \\
\hline Hand to mouth & $56(14.5)$ \\
\hline Eye contact & $17(4.4)$ \\
\hline Sexual transmission & $7(1.8)$ \\
\hline Don’t know & $14(3.6)$ \\
\hline \multicolumn{2}{|l|}{ Knowledge of COVID-19 symptoms } \\
\hline Knowledge of 3 or more correct symptoms & $118(46.6)$ \\
\hline Knowledge of less than 3 correct symptoms & $108(42.7)$ \\
\hline Don’t know & 27(10.7) \\
\hline \multicolumn{2}{|l|}{ Can COVID-19 be transmitted from mother to child? } \\
\hline Yes & $105(41.5)$ \\
\hline No & $15(5.9)$ \\
\hline Don’t know & $133(52.6)$ \\
\hline \multicolumn{2}{|c|}{ What is the mode of transmission from mother to child? } \\
\hline Trans-placental & 27(10.7) \\
\hline Droplets from infected mother after birth & $44(17.3)$ \\
\hline Breast milk & 21(8.3) \\
\hline Don't know & 161(63.7) \\
\hline \multicolumn{2}{|c|}{ Can COVID-19 infected mother breastfeed her baby? } \\
\hline Yes & $61(24.2)$ \\
\hline No & $53(20.9)$ \\
\hline Don’t know & 139(54.9) \\
\hline \multicolumn{2}{|l|}{ Can COVID-19 be treated? } \\
\hline Yes & 176(69.6) \\
\hline No & $15(5.9)$ \\
\hline Don't know & $62(24.5)$ \\
\hline \multicolumn{2}{|l|}{ Is COVID-19 preventable? } \\
\hline Yes & 231(91.3) \\
\hline No & $0(0.0)$ \\
\hline Don’t know & $22(8.7)$ \\
\hline \multicolumn{2}{|l|}{ Knowledge of the methods of prevention } \\
\hline Knowledge of at least 2 methods & 213(84.2) \\
\hline Knowledge of 1 method & $12(4.7)$ \\
\hline Don't know & $28(11.1)$ \\
\hline \multicolumn{2}{|l|}{ Can COVID-19 lead to death? } \\
\hline Yes & 242(95.7) \\
\hline No & $1(0.3)$ \\
\hline Don’t know & $10(4.0)$ \\
\hline \multicolumn{2}{|l|}{ Which group of people are at risk of death? } \\
\hline Children & $4(1.7)$ \\
\hline Young adults & $6(2.5)$ \\
\hline Middle age & $9(3.7)$ \\
\hline Old age & 223(92.1) \\
\hline \multicolumn{2}{|l|}{ What is physical distancing? $\left(n^{*}=408\right)$} \\
\hline Not talking or greeting people & 13(5.4) \\
\hline Not hugging or embracing & 176(73.3) \\
\hline Maintaining $2 \mathrm{~m}$ distance away from people & 219(91.3) \\
\hline
\end{tabular}
$n *=$ Multiple responses 


\section{Attitudes of respondents to COVID-19 pandemic}

Of the 253 respondents, 244(96.4\%) protected themselves whereas only $44(17.4 \%)$ protected their children. Two hundred and twenty $(87.7 \%)$ respondents admitted COVID-19 was real, 198(78.3\%) were willing to take COVID-19 test and $212(87.2 \%)$ were willing to go to the hospital if sick with COVID-19 infection. Only $48(19.0 \%)$ were willing to take the vaccine when made available while $46(18.2 \%)$ would be willing to vaccinate their children. Fifty-one (20.2\%) respondents had overall good attitude towards the COVID-19 pandemic whereas 202(79.8\%) had poor attitude, Table III.

Table III: Attitudes of respondents to COVID-19 pandemic

\begin{tabular}{|lc|}
\hline Variables & Frequency, $\mathbf{n}=\mathbf{2 5 3}(\mathbf{\%})$ \\
\hline Do you protect yourself? & $24496.4)$ \\
Yes & $9(3.6)$ \\
No & \\
Do you protect your children? & $44(17.4)$ \\
Yes & $209(82.6)$ \\
No & $222(87.7)$ \\
Is COVID-19 real? & $31(12.3)$ \\
$\quad$ Yes & $198(78.3)$ \\
No & $55(21.7)$ \\
Are you willing to take COVID-19 test? & \\
Yes & $212(87.2)$ \\
No & $16(6.6)$ \\
What actions to take if you are sick with COVID-19 infection? \\
$\mathrm{n}^{*}=267$ \\
$\quad$ Go to the hospital for treatment \\
$\quad$ Self-medication & $9(3.7)$ \\
Take herbs & $25(10.3)$ \\
Go for prayers & $5(2.1)$ \\
Do nothing & \\
Are you willing to take COVID-19 vaccine? & $48(19.0)$ \\
Yes & $205(81.0)$ \\
No & \\
Would you be willing to immunize your child? & $46(18.2)$ \\
Yes & \\
No & $207(81.8)$ \\
\hline
\end{tabular}

\section{Practice of preventive measures}

Two hundred and forty-three (96.0\%) respondents wore face mask while only $100(41.2 \%)$ wore face mask all the time outside their homes and 31(12.3\%) wore their children face mask. Majority, $155(57.6 \%)$ used fabric mask whereas only $62(23.1 \%)$ and $7(2.6 \%)$ used surgical and N95 mask respectively. Of 137 respondents who used cloth and fabric mask, $134(56.5 \%)$ washed their mask daily whereas of 7 who used N95 mask, 4(57.1\%) changed their mask daily. Twenty-five
(58.1\%) respondents did not wear face shield alone while 201(79.4\%) did not shake hands. Although 218(86.2\%) maintained physical distance, only 63(28.9\%) maintained physical distance all the time. Hands were washed with soap and water by $242(95.7 \%)$ respondents with 113(46.9\%) doing this at all times. Antibacterial hand sanitizers were used by $189(74.7 \%)$ respondents with 56(29.6\%) using it all the time. Overall good practice of preventive measures was observed by $67(26.5 \%)$ respondents while $186(73.5 \%)$ had poor practice, Table IV.

\begin{tabular}{|c|c|}
\hline Variables & Frequency, $n=253(\%)$ \\
\hline \multicolumn{2}{|c|}{ Do you wear face mask? } \\
\hline Yes & 243(96.0) \\
\hline No & $10(4.0)$ \\
\hline \multicolumn{2}{|c|}{ How often do you wear face mask outside the home? } \\
\hline All the time & $100(41.2)$ \\
\hline Most times & $89(36.6)$ \\
\hline Few hours daily & $54(22.2)$ \\
\hline \multicolumn{2}{|c|}{ Do your children wear face mask? } \\
\hline Yes & $31(12.3)$ \\
\hline No & $22(87.7)$ \\
\hline \multicolumn{2}{|c|}{ What type of face mask is worn? $n^{*}=269$} \\
\hline Piece of cloth & $45(16.7)$ \\
\hline Fabric mask & $155(57.6)$ \\
\hline Surgical mask & $62(23.1)$ \\
\hline N95 mask & $7(2.6)$ \\
\hline \multicolumn{2}{|c|}{ Is fabric/cloth mask washed daily? } \\
\hline Yes & 134(56.5) \\
\hline No & 103(43.5) \\
\hline \multicolumn{2}{|c|}{ Is N95 mask changed daily? } \\
\hline Yes & $4(57.1)$ \\
\hline No & 3(42.9) \\
\hline \multicolumn{2}{|c|}{ Do you wear face shield? } \\
\hline Yes & $43(17.0)$ \\
\hline No & $210(83.0)$ \\
\hline \multicolumn{2}{|c|}{ Do you wear face shield alone? } \\
\hline Yes & $18(41.9)$ \\
\hline No & $25(58.1)$ \\
\hline \multicolumn{2}{|c|}{ Do you shake hands? } \\
\hline Yes & $52(20.6)$ \\
\hline No & 201(79.4) \\
\hline \multicolumn{2}{|c|}{ Do you maintain physical distance? } \\
\hline Yes & $218(86.2)$ \\
\hline No & $35(13.8)$ \\
\hline \multicolumn{2}{|c|}{ How often is physical distance observed? } \\
\hline All the time & $63(28.9)$ \\
\hline Most times & $11(52.3)$ \\
\hline Few times & $41(18.8)$ \\
\hline \multicolumn{2}{|c|}{ Do you wash your hands with soup and water? } \\
\hline Yes & 242(95.7) \\
\hline No & $11(4.3)$ \\
\hline \multicolumn{2}{|c|}{ How often are your hands washed with soup and water? $(n=242)$} \\
\hline All the time & $113(46.7)$ \\
\hline Most times & $77(31.8)$ \\
\hline Few times & $52(21.5)$ \\
\hline \multicolumn{2}{|c|}{ Do you use antibacterial hand sanitizers? } \\
\hline Yes & 189(74.7) \\
\hline No & $4(25.3)$ \\
\hline \multicolumn{2}{|c|}{ How often do you use antibacterial hand sanitizers? } \\
\hline All the time & $56(29.6)$ \\
\hline Most times & $91(48.1)$ \\
\hline Few times & $42(22,2)$ \\
\hline
\end{tabular}


Boma Awoala West et.al. Knowledge, attitudes and practices of pregnant women attending the antenatal clinic of Rivers State University Teaching Hospital, Nigeria towards the coronavirus (COVID-19) pandemic.

Knowledge of symptoms of COVID-19 by respondents

The commonest symptoms of COVID-19 recalled by the respondents were cough 169(27.8\%), shortness of breath $153(25.1 \%)$ and fever $145(23.7 \%)$ while the least was redness of the eyes $1(0.2 \%)$, Figure 1.

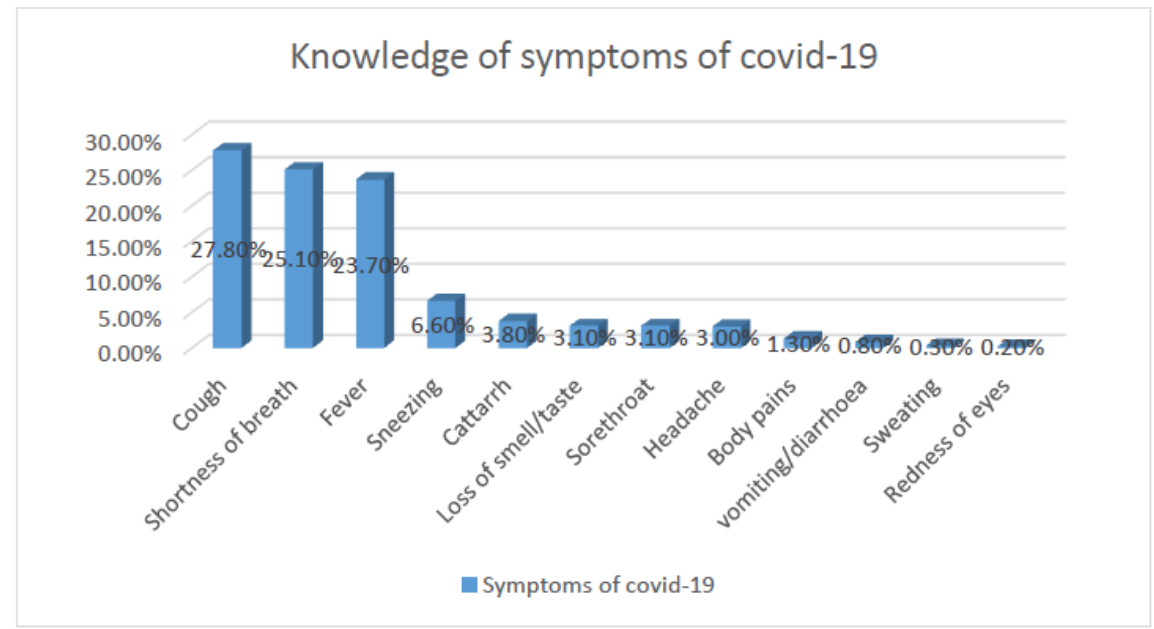

Figure 1: Knowledge of symptoms of covid-19 by respondents

\section{Association of sociodemographic features with knowledge, attitudes and practices of pregnant women towards covid-19 pandemic}

Parity, mother's level of education, mother's occupation, husband's level of education and husband's occupation were significantly associated with the knowledge of COVID-19 pandemic while age of the mothers was associated with the attitude towards COVID-19 pandemic. Parity, mother's level of education, mother's occupation, husband's level of education and husband's occupation were significantly associated with the practice towards COVID-19 infection prevention ( $\mathrm{P}$ value < 0.05), Table V.

Table V: Association of sociodemographic features with knowledge, attitudes and practices of pregnant women towards COVID-19 pandemic

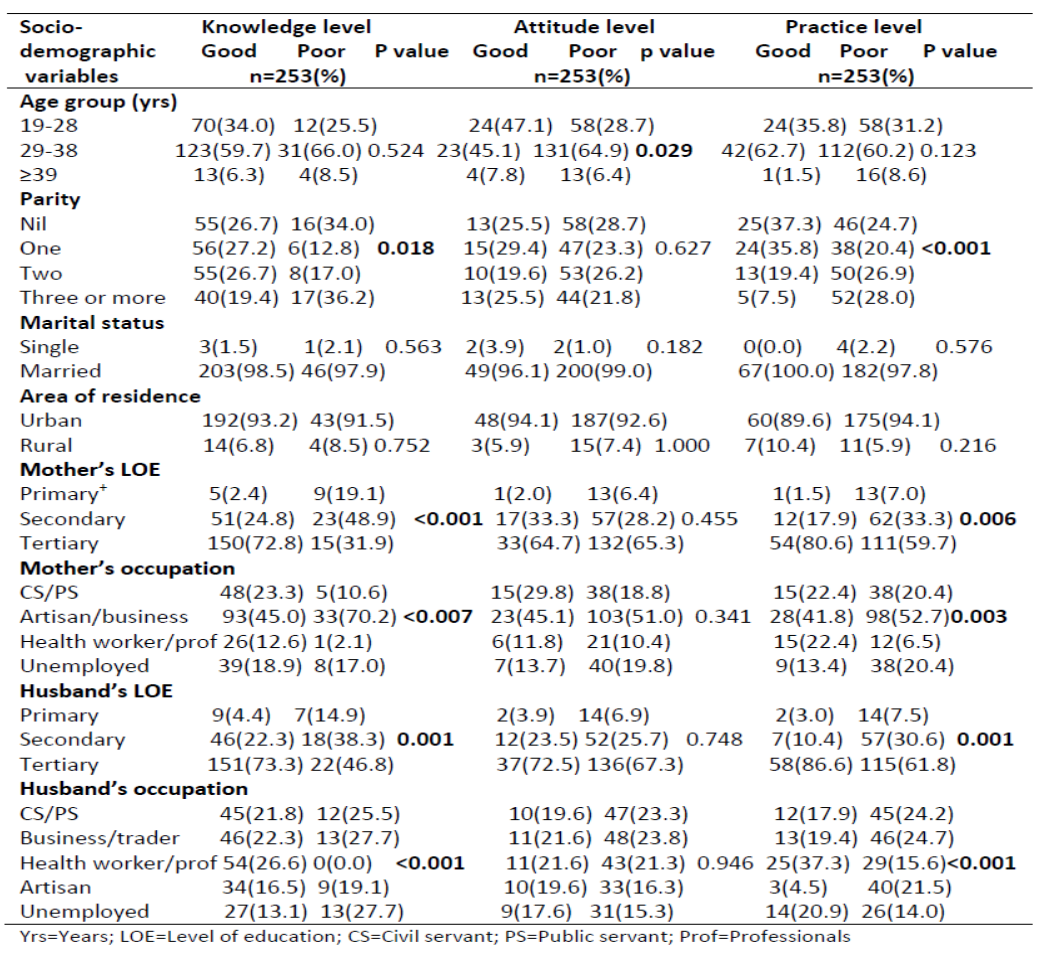




\section{Associations of knowledge, Attitude and Practice levels of pregnant women towards COVID-19 pandemic}

There was an association of good knowledge and good attitude levels with good practice level $(\mathrm{P}$ value $>0.05)$, Table VI.

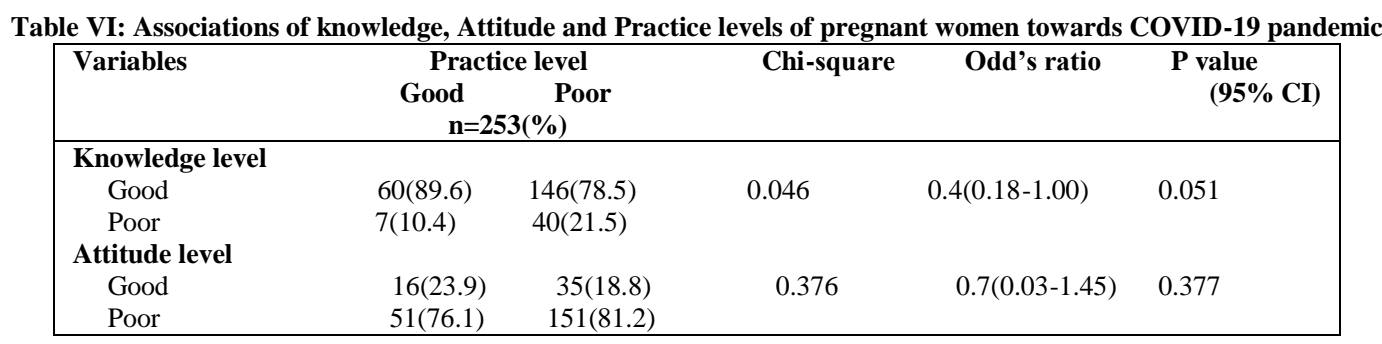

\section{DISCUSSION}

The commonest age group documented in the present study was 2938 year olds with a mean age of $30.78 \pm$ 4.71years. This was comparable with similar age groups of 30-39years, 3135years, 30-34years, 25-35years and 1839 years reported by Ejeh et al, ${ }^{[14]}$ Anikwe et al, ${ }^{[15]}$ Omozuwa et $a l,{ }^{[16]}$ Edet et $\mathrm{al}^{[17]}$ and Reuben et $\mathrm{al}^{[18]}$ respectively. This however contrast the lower age groups of 12-24years, 20-29years, 20-29years, 21-30years and < 25years documented by Sayedahmed et al, ${ }^{[19]}$ Nicholas et al, ${ }^{[20]}$ Hoque et $a l,{ }^{[21]}$ Ogbole et $\mathrm{al}^{[22]}$ and Kamal et $\mathrm{al}^{[23]}$ respectively. A predominantly high age group of $>50 y e a r s$ was however observed by Ayinde et al. ${ }^{[2]}$ These varying age group predominance could be attributed to different study populations and varying geographic locations.

Majority of respondents in the present study were urban residents as was also documented in Abakaliki ${ }^{[15,25]}$ southeast and North-central Nigeria. ${ }^{[18]}$ This is not surprising as all studies were carried out in health facilities located in urban areas of the states. Okello et $\mathrm{al}^{[26]}$ on the contrary, reported predominance of rural dwellers. This difference could be due to different study population recruited.

Most respondents had tertiary level of education as was also observed in other cities in Nigeria, ${ }^{[6,15,17,18,22,27-29]}$ India, ${ }^{[23]}$ Uganda, ${ }^{[26]}$ Chad $^{[30]}$ and China. ${ }^{[31]}$ In contrast, secondary level of education predominated in Benin, ${ }^{[16]}$ southern Nigeria.
The reason for the high predominance of secondary school leavers in Benin could not be ascertained as it is situated in the urban area where level of education is expected to be high.

There was an overall high knowledge of COVID-19 pandemic of $81.4 \%$ in the present study amongst pregnant women. This is not surprising as majority of the respondents had tertiary education and thus well read. This high knowledge level corroborates the $85.3 \%$, $86.6 \%$ and $88.75 \%$ documented by Omozuwa et al, ${ }^{[16]}$ Edet et al ${ }^{[17]}$ and Ejeh et $\mathrm{al}^{[14]}$ in Nigeria but lower than the over $90 \%$ and $90 \%$ reported by Anozie et $\mathrm{al}^{[25]}$ and Zhong et $\mathrm{al}^{[31]}$ in Abakaliki south-east Nigeria and China respectively. Lower knowledge levels of $78.7 \%, 60.7 \%, 30.47 \%$, $75.3 \%, 43 \%, 68.3 \%$ and $21.9 \%$ were reported in Nigeria, ${ }^{[6,32,27]}$ India, ${ }^{[23]}$ South Africa, ${ }^{[21]}$ Sudan $^{[19]}$ and Cameroon ${ }^{[20]}$ respectively. This varying knowledge could be attributable to the varying study population and time of study in relation to when the pandemic began as well as difference in the questions asked in the various studies. High knowledge levels were also observed in other studies ${ }^{[14,33]}$ in which the study population were health care workers. There is also the tendency that studies carried out much later after the pandemic began had a better knowledge level $^{[25]}$ than those carried out during the early months of the pandemic. ${ }^{[32]}$ It is worthy of note however that the wide media coverage of COVID-19 by the federal, state 
and local government in Nigeria as well as the strict control measures instituted by the government and its agencies may have contributed to the high knowledge level attained by respondents in the present study.

Majority (99.2\%) of respondents had heard of COVID-19 in the present study. Similarly, $93.2 \%$ and $89.3 \%$ of respondents in Cameroon ${ }^{[20]}$ and Yobe state, ${ }^{[33]}$ northeast Nigeria respectively had heard of covid-19 while all (100\%) respondents had heard of the virus in other parts of Nigeria. ${ }^{[14,33]}$ Interestingly, the $100 \%$ of respondents who had heard of COVID-19 were all health care workers.

Commonest source of information in the present study was from television $(32.6 \%)$ followed by radio $(21.7 \%)$ and social media $(19.3 \%)$. Television being the commonest source of information was also reported by Adesegun et al, ${ }^{[6]}$ Anikwe et al, ${ }^{[15]}$ Nicholas et al ${ }^{[20]}$ and Okello et al. ${ }^{[26]}$ In contrast, social media was the commonest source of information by Ejeh et al, ${ }^{[14]}$ Reuben et al, ${ }^{[18]}$ Sayedahmed et al ${ }^{[19]}$ Habib et $\mathrm{al}^{[27]}$ and Egbi et al. ${ }^{[28]}$

Close to $2 / 3^{\text {rd }}(65.6 \%)$ of the respondents knew that COVID-19 was a viral disease. Much higher knowledge level was observed in Northern Nigeria ${ }^{[27]}$ $(73.1 \%)$, Cameroon ${ }^{[20]}(77.1 \%)$, Onitsha, ${ }^{[15]}$ south-east Nigeria $(88.0 \%)$, Oyo state, ${ }^{[24]}$ south-west Nigeria (88.6\%), north-central Nigeria $^{[18]}(91.9 \%)$ and Abakaliki, ${ }^{[25]}$ southeast Nigeria $(98.4 \%)$. A lower knowledge level $(60 \%)$ was however documented in Onitsha, ${ }^{[32]}$ south-east Nigeria. This varying knowledge level could be attributed to the educational level of the study population as well as their professions. The high knowledge level observed in Abakaliki could be because the study population were only health care workers as compared to the present study which comprised of pregnant women.

Majority of the respondents in the present study identified transmission of COVID-19 infection via droplets from air $(60.7 \%)$ and contact with infected surfaces $(51.6 \%)$. Air droplets was similarly documented as the commonest mode of transmission in Nigeria ${ }^{[18,25,27,29,32]}$ and India. ${ }^{[23]}$ Contrary to the present study however, human and animal modes of transmission accounted for $38 \%$ and $32 \%$ respectively followed by air droplets $(30 \%)$ in Abakaliki, ${ }^{[15]}$ south-east Nigeria whereas in Cameroon, ${ }^{[20]} 74.6 \%$ identified direct contact, $51.9 \%$ air droplets and $45.2 \%$ contact with infected surfaces.

Less than half $(41.5 \%)$ of the respondents knew that COVID-19 could be transmitted to their babies as also documented in Singapore ${ }^{[34]}(47 \%)$ and Yenagoa, ${ }^{[29]}$ Nigeria $(65.6 \%)$. This information is key to the attitude and practice of pregnant women towards the expected preventive measures.

The overall level of good attitude of respondents towards the covid-19 pandemic in the present study of $20.2 \%$ was similar to the $25 \%$ documented in South Africa ${ }^{[21]}$ and $17.8 \%$ in Kano, ${ }^{[27]}$ northern Nigeria. Similarly, low percentage of good attitude of $51.5 \%$ and $56.4 \%$ were reported in Uganda $^{[26]}$ and Onitsha, ${ }^{[32]}$ south-east Nigeria respectively. The poor attitude of respondents in the present study may thus mitigate the efforts made by the government to curb the infection. Better percentages of $73.9 \%, 80.6 \%$ and $89.9 \%$ were however observed in India, ${ }^{[23]}$ Port Harcourt, ${ }^{[17]}$ southern Nigeria and Sudan ${ }^{[19]}$ respectively. These variances could be attributed to the varying criteria for assessment, different cut-off values used, levels of education, varying age groups as well as varying study population. It is pertinent to note that although the respondents had good knowledge level of COVID-19, they exhibited poor attitude towards the disease. This therefore calls for more enlightenment campaigns among the populace.

More than $3 / 4^{\text {th }}(87.7 \%)$ believed COVID-19 is real in the present study as also observed by other researchers. ${ }^{[6,14,33]}$ In contrast, a study carried out among the general population in Kano, ${ }^{[27]}$ northern Nigeria showed that $36 \%$ of the respondents 
believed that covid-19 was a man-made virus.

Surprisingly, less than quarters $(19 \%)$ of the respondents were willing to take the vaccine or allow their children to do same. This contrast the $70 \%$ of the general population including health workers in the study in $\mathrm{Kano}^{[27]}$ who were willing to take the vaccine once made available. The reason for this wide disparity could also be attributed to the fact that a good number of the study population in the Kano ${ }^{[27]}$ study were health workers. Special attention in relation to prevention, prompt diagnosis and management of COVID-19 is therefore important in order to protect pregnant women who are vulnerable and by extension, their unborn babies.

An overall good practice towards the prevention of COVID-19 in the present study of $26.5 \%$ was comparable to $25.96 \%$ documented in Kano, ${ }^{[27]}$ northern Nigeria. Similarly, low practice levels of $48.3 \%$, $48.5 \%, 53.6 \%$ and $58 \%$ were reported in Uganda, ${ }^{[26]}$ Sudan $^{[19]}$ and Nigeria ${ }^{[32,17]}$ respectively whereas good practice levels of $75.6 \%$ and $77.1 \%$ were documented in other parts of Nigeria. ${ }^{[6,16]}$ These differences could be attributed to the varying cut-off percentages that define good and poor practice levels in the various studies, cultural differences as well as the educational status of the respondents. It is also surprising to note that although there was good knowledge of the disease condition, the practice level towards its prevention was very low. This could thus be responsible for the increasing number of cases in the country.

Although majority (96\%) of respondents admitted to wearing face mask, only $39.5 \%$ wore face mask all the time outside their homes in the present study. Similarly, Egbi et al $^{[28]}$ in Bayelsa reported $43.5 \%$ among health workers while Mustapha et $\mathrm{al}^{[33]}$ in Yobe state, Nigeria documented $35 \%$ among the general population. Slightly higher rates were reported by Omozuwa et $\mathrm{al}^{[16]}$ in Benin $58.1 \%$ among pregnant women and $59.2 \%$ by Ejeh et $\mathrm{al}^{[14]}$ among the general population in 6 geo-political zones in Nigeria. Much higher rates of $79.5 \%$, $87.5 \%, 88.6 \%, 98 \%$ and $99 \%$ were documented in other parts of Nigeria, ${ }^{[18,29,16]}$ China $^{[31]}$ and India ${ }^{[23]}$ respectively. This low usage of face mask in the present study could be attributed to non-availability, high cost of medical mask as well as the discomfort in the use of face mask especially in the tropics. This thus calls for more public enlightenment campaigns on the importance of the regular use of face mask in the prevention of the spread of COVID-19 and free distribution of face mask by the government.

Of the majority (95.7\%) of respondents who admitted to washing their hands with soap and water in the present study, less than half (46.9\%) did so all the time. Poor regular hand washing practice of $45.2 \%$ and $56 \%$ were also reported in Benin, ${ }^{[16]}$ Nigeria and Sudan. ${ }^{[19]}$ Good regular hand washing practice of $76.4 \%$, $82 \%, 87.9 \%, 91.1 \%, 95.3 \%$ and $99 \%$ were however reported in other parts of Nigeria $^{[25,29,33,28,24]}$ and India ${ }^{[23]}$ respectively. Interestingly, similar study carried out among health care workers in Yobe state, ${ }^{[33]}$ Nigeria documented $100 \%$ hand washing practice. This is not surprising as the sample population being front-liners in the fight against COVID-19 pandemic are the most informed group in the society and as such expected to have better practice level.

Although almost $3 / 4^{\text {th }}(74.7 \%)$ of respondents admitted to the use of alcoholbased hand sanitizers, only about a quarter $(29.6 \%)$ did so all the time. Similar good practice $(87.9 \%)$ was documented in Bayelsa $^{[28]}$ whereas poor practice was observed in Abakaliki ${ }^{[25]}(67.4 \%)$ and Benin, ${ }^{[16]}$ Nigeria $(50.5 \%)$. This poor practice could be attributable to unavailability and high cost of these antibacterial sanitizers.

Physical distancing was maintained by more than $3 / 4^{\text {th }}(86.2 \%)$ of respondents, although only about a quarter (28.9\%) complied all the time. Poor physical 
distancing of $56 \%$ and $54 \%$ were also practiced in other parts of Nigeria. ${ }^{[25,33]}$

The respondents in the present study recalled cough as the commonest symptom of COVID-19 infection followed by shortness of breath and fever. Similar observation was made by Reuben et $\mathrm{al}^{[18]}$ in their study in north-central Nigeria. Fever was recalled as the commonest symptom in other parts of Nigeria $^{[15,29]}$ and Sudan ${ }^{[19]}$ whereas cough was documented in Cameroon. ${ }^{[20]}$ Contrary to these studies, Adesegun et $\mathrm{al}^{[6]}$ in his cross-sectional study of the general population of literate Nigerians documented difficulty in breathing as the commonest symptom recalled followed by cough and fever.

Parity, level of education of mother and spouse as well as occupation of mother and spouse were significantly associated with the knowledge of COVID-19 in the present study. Edet et $\mathrm{al}^{[17]}$ observed occupation and level of education to be significantly associated with knowledge of COVID-19 while age groups and occupation of respondents were significantly associated with knowledge as reported also by Adesegun et al. ${ }^{[6]}$ In the present study, respondents and their spouses with tertiary level of education had significantly good knowledge level as compared to those with lower levels of education. This was in consonance with the study by Egbi et al ${ }^{[28]}$ who documented a higher mean knowledge score among respondents with tertiary education than those with secondary level of education. Health workers and professionals in the present study had significantly good knowledge level than all other occupations. This was similar to the findings by Egbi et $\mathrm{al}^{[28]}$ where nurses and doctors had significantly higher mean knowledge scores than the others thus corroborates with findings by Adesegun et $\mathrm{al}^{[6]}$ in their multiple regression model which showed that respondents with medical related occupation were 6.5times more likely to have better knowledge than the unemployed. Respondent's age group, marital status and area of residence were however not associated with knowledge of COVID-19 in the present study. Age was also not significantly associated with knowledge of COVID-19 as documented also by Edet et al. ${ }^{[1]}$

Age groups were significantly associated with the attitude of respondents towards COVID-19 in the present study as also observed by Adesegun et $\mathrm{al}^{[6]}$ and Ejeh et al. ${ }^{[14]}$ Although age was not significantly associated with the attitude of respondents as documented by Edet et al ${ }^{[17]}$ in an earlier study in Port Harcourt, occupation and the level of education were. Okello et $\mathrm{al}^{[26]}$ documented significant difference in the level of education in respect to the attitude of respondents whereas Kamal et $\mathrm{al}^{[23]}$ documented age, level of education and place of residence being significantly associated with the attitudes of respondents.

Practice level of the respondents in the present study differed significantly with respect to parity, level of education and occupation of pregnant women and their spouses. Egbi et al ${ }^{[28]}$ also reported that respondents with post-graduate and graduate degree had a significantly higher practice score compared with those with secondary level of education. Contrary to the present study, age was significantly associated with COVID-19 related practices as documented by Edet et al. ${ }^{[17]}$ Kamal et al ${ }^{[23]}$ observed that practice scores had a significant association with age and place of residence whereas Adesegun et $\mathrm{al}^{[6]}$ in their study did not find any significant difference in the practice levels of respondents in respect to age, occupation, marital status, level of education and area of residence. Marital status was not significantly associated with knowledge, attitude and practice levels towards COVID-19 prevention in the present study as similarly observed by Edet et al. ${ }^{[17]}$

It is worthy of note that good practice level in the present study was associated with good knowledge and good attitude level although this association was not statistically significant. This therefore 
denotes that good knowledge may not always influence good attitude and good practice as observed in the present study although knowledge is a prerequisite for forming positive attitude, behaviour and practice. Similar association in an earlier study among clients seeking care in primary health care facilities in all the 23 local government areas of Rivers State, ${ }^{[17]}$ Nigeria was statistically significant. This difference could be attributable to the much larger sample size in the latter study as well as the much wider coverage. Similarly, Adesegun et $\mathrm{al}^{[6]}$ reported that good attitude and practice grades had significantly higher knowledge scores. In addition, Reuben et $\mathrm{al}^{[18]}$ also documented significant relationship between knowledge of covid19, attitude and perception.

Limitation of this study is the small sample size and the fact that the study was carried out in only one centre.

\section{CONCLUSION}

Although majority of the pregnant women $(81.4 \%)$ attending ANC at RSUTH had good knowledge of the Covid-19 infection, there was poor attitude and poor practice of preventive measures towards the pandemic. The commonest symptoms of COVID-19 recalled by the respondents were cough, shortness of breath and fever. Parity, mother's level of education, mother's occupation, husband's level of education and husband's occupation were significantly associated with the knowledge of COVID19 infection while age of the mothers was associated with the attitude towards COVID-19 infection. Practice level of the respondents differed significantly with respect to parity, level of education and occupation of mothers and their spouses. Our findings suggest that good knowledge although required for the acquisition of positive attitudes, may not always influence good attitude and good practice. We thus recommend strengthening of public health education campaigns to the general public and at risk groups such as pregnant women (taking advantage of opportunities such as health talks during ANC and via television, radio and social media), updates on preventive measures, provision of evidencebased policies and debunking of wrong beliefs.

\section{Acknowledgement}

We hereby appreciate all the research assistants, the nurses at the antenatal clinics and the pregnant women who gave consent to be enrolled into the study.

There was no external funding. The research was fully funded by the researchers.

\section{Conflict of Interest: None}

\section{Source of Funding: None}

\section{Ethical Approval: Approved}

\section{REFERENCES}

1. World Health Organization, 2020. Situation Reports. Geneva, Switzerland: WHO. Available at: Https: //www.who.int/emergencies/diseases/novelcoronavirus-2019/situation-

reports/Accessed February 5, 2020.

2. Rasmussen SA, Smulian JC, Lednicky JA, et al 2020. Coronavirus Disease 2019(COVID-19) and Pregnancy: What Obstetricians need to know. Am J Obstet Gynaecol 222:415-426.

3. Poon LC, Yang H, Kapur A, et al. Global Interim Guidance on Coronavirus Disease 2019 (COVID-19) during Pregnancy and Puerperium from FIGO and Allied Partners: Information for Healthcare Professionals. IJGO 2020; https://doi.org/10.1002/IJGO.13156.

4. WHO. WHO Coronavirus Disease (COVID-19) Dashboard. https://covid19. who.int/?gclid=Cj0KCQjww _f2BRCARIsAP3zarGxeg_Tx4IC3YW_sB hh-Q9RNu-hIg-KMu9IOp_YSLbUcIVF8HcHDoaAtmmEAL_wcB Assessed March 9, 2021

5. Maharlouei N, Asadi N, Bazrafsshan K, et al. Knowledge and Attitude regarding COVID-19 among Pregnant Women in Southwestern Iran in the Early Period of its 
Boma Awoala West et.al. Knowledge, attitudes and practices of pregnant women attending the antenatal clinic of Rivers State University Teaching Hospital, Nigeria towards the coronavirus (COVID-19) pandemic.

Outbreak: A Cross-Sectional study. Am J Trop Med Hyg 2020; 103(6): 2368-75.

6. Adesegun OA, Binuyo T, Adeyemi O, et al. The COVID-19 Crises in Sub-Saharan Africa: Knowledge, Attitudes, and Practices of the Nigerian Public. Am J Trop Med Hyg. 2020 Nov; 103(5): 1997-2004.

7. D'Amico F, Baumgart DC, Danese S, et al 2020. Diarrhoea during COVID-19 Infection: Pathogenesis, Epidemiology, Prevention and Management. Clin Gastroenterol Hepatol 18: 1663-1672.

8. World Health Organization, 2020. Myth Busters. Geneva, Switzerland: WHO. Available at https://www.who.int/images/defaultsource/health-topics/coronavirus/mythbusters/web-mythbusters/mythbuster4.png?sfvrsn=e163bada_8.

9. Nwafor JI, Aniukwu JK, Anozie BO, et al. Pregnant Women's Knowledge and Practice of Preventive Measures against COVID-19 in a Low-Resource African Setting. Int $\mathbf{J}$ of Obstet and Gynecol 2020; 150(1): 121-123. https://doi.org/10.1002/ijgo.13186

10. Qiao J. What are the Risks of COVID-19 Infection in Pregnant Women? The Lancet 2020; 395(10226): 760-62.

11. Allotey J, Stallings E, Bonet $\mathrm{M}$, et al. Clinical Manifestations, Risk Factors, and Maternal and Perinatal Outcomes of Coronavirus Disease 2019 in Pregnancy: Living Systematic Review and MetaAnalysis. BMJ 2020; 370:3320. Doi.10.1136/bmj.m3320.PMID: 32873575; PMCID: PMC7459193

12. World Health Organisation. Coronavirus Disease (COVID-19) Advice for the Public [WHO website] 2020. https://www.who.int/emergencies/diseases/n ovel-coronavirus-2019/advice-for-public.

13. Omrani AS, Shalhoub S. Middle East Respiratory Syndrome Coronavirus (MERSCoV): What lessons can we learn? J Hosp Infect 2015; 91: 188-196

14. Ejeh FE, Saidu AS, Onoichio S, et al. Knowledge, Attitude and Practice among Healthcare Workers towards COVID-19 Outbreak in Nigeria. Heliyon 6(2020) e05557.

https://doi.org/10.10161/j.heliyon.2020.e05 557

15. Anikwe CC, Ogah CO, Anikwe IH, et al. Coronavirus Disease 2019: Knowledge, Attitude and Practice of Pregnant Women in a Tertiary Hospital in Abakaliki, Southeast Nigeria. Int J Gynecol Obstet 2020; 151:197-202.

https://doi.org/10.1002/ijgo.13293

16. Omozuwa ES, Uwaibi NE, Erhabor JO. Level of Practice of Safety Precautions against COVID-19 among Pregnant Women attending Antenatal Clinic in Central Hospital, Benin, Benin City in Nigeria. J Appl Sci Environ Manage 2020; 24(11): 1925-1931

DOI: https://dx.doi.org/10.4314/jasem.v24:11.12

17. Edet CK, Wegbom AI, Kiri VA. Knowledge, Attitude and Practice of Clients towards COVID-19 at Primary Health Care Facilities in Rivers State, Nigeria. Research Square DOI: https://doi.org/10.21203/rs40966/v1

18. Reuben RC, Danladi MMA, Saleh DA, et al. Knowledge, Attitudes and Practices towards COVID-19: An Epidemiological Survey in North-Central Nigeria. J Community Health 2020. https://doi.org/10.1007/s10900-020-00881-1

19. Sayehahmed AMS, Abdalla AAA, Khalid MHM. Knowledge, Attitude and Practice regarding COVID-19 among Sudanese Population during the Early Days of the Pandemic: Online Cross-Sectional Survey. J Scientific African 2020; 10 e00652 https://doi.org/10.1016/j.sciaf.2020.e00652

20. Nicholas T, Mandaah FV, Esemu SN, et al. COVID-19 Knowledge, Attitudes and Practices in a Conflict affected area of South West Region of Cameroon. Pan Afr Med J 2020; 35(2): 34 . DOI: 10.11604/pamj.2020.35.2.22963

21. Hoque AM, Alam AM, Hoque M, et al. Knowledge, Attitudes and Practices towards COVID-19 of Pregnant Women at a Primary Health Care Facility in South Africa. Eur J Med Health Sci 2021; 3(1): 50-55. DOI: http://dx.doi.org/10.24018/ejmed.2021.3.1.6 54

22. Ogbole AJ, Bisji JS, Umar SJ, et al. Knowledge, Attitudes and Perception in Regard to COVID-19 Pandemic in Nigerian Military Population. Adv Soc Sci Res J 2020; 7(11): 231-249. DOI: https://doi.org/10.14738/assrj.711.9254

23. Kamal D, Thakur VD, Swain SK, et al. Knowledge, Attitude and Practice towards COVID-19 among Pregnant Women in a Tertiary Care Hospital during the COVID- 
Boma Awoala West et.al. Knowledge, attitudes and practices of pregnant women attending the antenatal clinic of Rivers State University Teaching Hospital, Nigeria towards the coronavirus (COVID-19) pandemic.

19 Outbreak. J Marine Med Society 2021; 22(3): 66-71. DOI: 10.4103/jmms.jmms_81_20

24. Ayinde AA, Usman AB, Gbolahan A. A Cross-Sectional Study on Oyo State Health Care Workers Knowledge, Attitude and Practice regarding Coronavirus Disease 2019 (COVID-19). Adv Infect Dis 2020; 10(3): 6-15. doi: 10.4236/aid.2020.103002

25. Anozie OB, Ikeotuonye AC, Nwokporo EI, et al. Assessment of Knowledge, Attitude and Practice of COVID-19 Guidelines among Health Care Workers in Alex Ekweme Federal University Teaching Hospital, Abakalikki, Ebonyi State, Nigeria. Int J Res Med Sci 2021; 9(1): 39-44. DOI: https://dx.doi.org/10.18203/23206012.ijrms202005828

26. Okello G, Izudi J, Teguzirigwa $S$, et al. Findings of a Cross-Sectional Survey on Knowledge, Attitudes and Practices about COVID-19 in Uganda: Implications for Public Health Prevention and Control Measures. Biomed Res Int 2020; Article ID 5917378. https://doi.org/10.1155/2020/5917378

27. Habib MA, Dayyab FM, Iliyasu G, et al. Knowledge, Attitude and Practice of COVID-19 Pandemic in Northern Nigeria. PLOS

ONE https://doi.org/10.1371/journal.pone.024517 6

28. Egbi OG, Duru C, Kasia B. Knowledge, Attitude and Practice towards COVID-19 among Workers of a Tertiary Hospital in Bayelsa State, Nigeria. Pan Afr Med J 2020; 37(1): $24 . \quad$ doi: 10.11604/pamj.supp.2020.37.1.26259

29. Allagoa DO, Oriji PC, Obagah L, et al. Knowledge, Attitudes and Practices towards COVID-19 among Pregnant Women in a Tertiary Hospital in South-South, Nigeria.
Int J Res Reports in Gynecol 2020; 3(3): 3541, Article No IJRRGY.64239

30. Dzomo GRT, Bernales M, Lopez R, et al. Knowledge, Attitudes and Practices regarding COVID-19 in N'Djamena, Chad. J Community Health 2021. https://doi.org/10.1007/s/0900-021-00963-8

31. Zhong B, Luo W, Li H, et al. Knowledge, Attitudes and Practices towards COVID-19 among Chinese Residents during the Rapid Rise Period of the COVID-19 Outbreak: A Quick On-line Cross-Sectional Survey. Int J Biol Sci 2020

32. Iloanusi NR, Iloanusi S, Mgbere O, et al. COVID-19 Related Knowledge, Attitude and Practices in a South-eastern City in Nigeria: A Cross-sectional Survey. Available at https://ssrn.com/abstract=3683769 or http://dx.doi.org/10.2139/ssrn.3683769

33. Mustapha T, Daskum AM, Gana AH. Assessment of Knowledge, Attitude and Practice on Prevention of Novel Corona Virus (COVID-19) in Yobe State, Northeast Nigeria. Int J Res and Review 2020; 7(11): 23-30

34. Lee RWK, Loy SL, Yang L, et al. Attitudes and Precaution Practices towards COVID19 among Pregnant Women in Singapore: A Cross-Sectional Survey. BMC Preg Childbirth 2020; 20: 675 https://doi.org/10.1186/s/2884-020-03378-w

How to cite this article: West BA, Aitafo JE, Kalio DGB. Knowledge, attitudes and practices of pregnant women attending the antenatal clinic of Rivers State University Teaching hospital, Nigeria towards the coronavirus (COVID-19) pandemic. Int J Health Sci Res. 2021; 11(4): 21-33. DOI: https://doi.org/ 10.52403/ijhsr.20210403 